\title{
Physiological significance of vitamin D produced in skin compared with oral vitamin D
}

\author{
David R. Fraser* (1) \\ Sydney School of Veterinary Science, Faculty of Science, The University of Sydney, RMC Gunn Building (B19), Sydney, NSW 2006, Australia \\ (Received 11 January 2022 - Final revision received 19 January 2022 - Accepted 25 January 2022) \\ Journal of Nutritional Science (2022), vol. 11, e13, page 1 of 5 \\ doi:10.1017/jns.2022.11 \\ Abstract \\ Since the discovery of vitamin D, it has been accepted that its physiological supply is either from food or by endogenous synthesis in skin exposed to solar \\ UV light. Yet vitamin D is a component of very few foods and its supply as a natural nutrient is unable to maintain good vitamin D status for human \\ populations. One aspect of vitamin D physiology that has been ignored is that the mechanisms for its transport and processing from these two sources are \\ quite different. Excess intake of vitamin D causes hypercalcaemic toxicity. However, experiments with different animal species have shown that long-term \\ supply of oral vitamin D in apparently non-toxic amounts causes atherosclerosis in large arteries. A mechanism for this toxicity is proposed. Alternative \\ strategies for addressing widespread vitamin $\mathrm{D}$ deficiency by food fortification should be considered in light of the angiotoxicity caused by oral vitamin $\mathrm{D}$ in \\ animal experiments.
}

Key words: 25-hydroxyvitamin D production: 25-hydroxyvitamin D toxicity: Angiotoxicity: Vitamin D transport

Since the discovery, more than 100 years ago, of the small molecules known as organic micronutrients or vitamins, it has been axiomatic that their physiological source is from food and that they enter the body by absorption from the alimentary tract. The explanation as to why these essential enzyme co-factors or cell regulating substances can be made by plants and bacteria and not by terrestrial animals is that evolutionary efficiency eliminates the metabolic synthesis of substances that can be reliably obtained from food. A specific example is the genetic loss of the enzyme L-gulono-gamma-lactone oxidase in primates and a few other vertebrate families ${ }^{(1)}$. This enzyme catalyses the final step in the biosynthesis of ascorbic acid (vitamin C). Its genetic loss removed a dispensable metabolic process from those species which had reliable dietary sources of vitamin C.

However, one of these organic micronutrients, vitamin $\mathrm{D}$, can be synthesised in humans and most other terrestrial vertebrates, but not by an enzyme-catalysed metabolic process.
Rather, vitamin D is produced in skin as a photochemical product from the action of UV light on its precursor, 7-dehydrocholesterol (7-DHC), when the skin is exposed to the sun ${ }^{(2)}$. Because vitamin D was discovered as a nutritional factor that prevented and healed the bone disease of rickets in dogs ${ }^{(3)}$, it has become accepted dogma that vitamin D supply can be either from food or by formation in $\operatorname{skin}^{(4)}$. With the discovery of the secosteroid structure of vitamin D and the ability for its commercial production as either cholecalciferol from 7-DHC or as ergocalciferol from the fungal and yeast sterol, ergosterol, food was able to be fortified to increase artificially the contribution of oral vitamin D to vitamin D status. Nevertheless, despite food fortification, it is apparent from the seasonal changes in vitamin D status of populations that the main supply of vitamin D is from its photochemical synthesis in skin by the action of solar UVB light ${ }^{(5)}$.

The natural foods that contain enough vitamin $\mathrm{D}$ to contribute to vitamin D status are fish, meat, milk, and eggs ${ }^{(6,7)}$.

Abbreviations: 7-DHC: 7-dehydrocholesterol; 25(OH)D: 25-hydroxy vitamin D; DBP: vitamin D-specific-binding protein

* Corresponding author: David R. Fraser, email: david.fraser@sydney.edu.au 
Table 1. Vitamin D content of unfortified food

\begin{tabular}{|c|c|c|c|c|c|c|c|c|}
\hline \multirow[b]{2}{*}{ Reference No. } & \multicolumn{2}{|c|}{ Vitamin $D_{3}$} & \multicolumn{2}{|c|}{$25(\mathrm{OH}) \mathrm{D}_{3}$} & \multicolumn{2}{|c|}{ Vitamin $D_{2}$} & \multicolumn{2}{|c|}{$25(\mathrm{OH}) \mathrm{D}_{2}$} \\
\hline & (6) & (7) & (6) & (7) & (6) & (7) & (6) & (7) \\
\hline $\operatorname{Milk}^{\mathrm{a}}(\mu \mathrm{g} / \mathrm{l})$ & 0.4 & 0.08 & 0.12 & 0.04 & 0.12 & - & - & - \\
\hline Egg $(\mu \mathrm{g} / \mathrm{egg})$ & 0.55 & 0.72 & 0.3 & 0.24 & - & - & - & - \\
\hline Beef $(\mu \mathrm{g} / 100 \mathrm{~g})$ & 0.12 & 0.06 & 0.17 & 0.16 & 0.17 & 0.027 & 0.06 & 0.063 \\
\hline Salmon $(\mu \mathrm{g} / 100 \mathrm{~g})$ & 8.7 & 8.7 & 0.18 & 0.18 & - & - & - & - \\
\hline
\end{tabular}

${ }^{\text {a }}$ Full-cream milk.

Hence, these would have been the nutritional sources of vitamin D before food fortification or oral supplements were available. It is likely that the vitamin D content of hen eggs is higher than before the discovery of vitamin $\mathrm{D}$, as the diet of high-producing egg-laying hens is now fortified with vitamin $\mathrm{D}$ to maintain egg-shell quality. Recent analyses of the amounts of vitamin $\mathrm{D}_{2}$, vitamin $\mathrm{D}_{3}$ and their 25-hydroxy metabolites in these foods of animal origin are summarised in Table 1. The oral intake of 25-hydroxy vitamin D $[25(\mathrm{OH}) \mathrm{D}]$ has been shown to be up to five times more effective than the parent molecule at raising the concentration of $25(\mathrm{OH}) \mathrm{D}$ in blood serum ${ }^{(8)}$. Therefore, a diet with varying amounts of these food components would supply up to $15 \mu \mathrm{g}$ of vitamin $\mathrm{D}$ equivalents per day. Dietary surveys of populations from around the world indicate, however, that the typical range of vitamin $\mathrm{D}$ daily intakes from unfortified food is from 0 to $5 \mu \mathrm{g} / \mathrm{d}^{(9)}$. It would follow that this would have been the range of daily intakes of vitamin $\mathrm{D}$ in human history before the discovery of this hormone precursor. Recommended daily intakes of vitamin D range from 10 to $15 \mu \mathrm{g}^{(10)}$, to maintain adequate vitamin $\mathrm{D}$ status, often defined as a serum $25(\mathrm{OH}) \mathrm{D}$ concentration of $>50 \mathrm{~nm}$.

How does this recommendation compare with the potential quantity of vitamin D produced by skin exposure to the sun? There are many variables that affect the efficiency of conversion of 7-DHC to vitamin $\mathrm{D}_{3}$. The most obvious is the seasonal variation in the intensity of solar UVB radiation, which accounts for the higher vitamin D status of populations in summer compared with winter ${ }^{(11)}$. Other variables include the decline in 7-DHC content of skin with age ${ }^{(12)}$, the proportion of body surface area exposed to the sun, the absorption of UVB radiation by skin pigmentation ${ }^{(13)}$ and the conversion of pre-vitamin $\mathrm{D}_{3}$ to inactive products, lumisterol and tachysterol, with prolonged exposure to UV radiation ${ }^{(14)}$. Bearing in mind these variables, the potential yield of vitamin $\mathrm{D}_{3}$ can still be estimated using modest values of 7-DHC $\mu \mathrm{g} /$ $\mathrm{cm}^{2}$, percentages of 7-DHC converted and percentages of the total skin area ${ }^{(15)}$ exposed (Table 2). It can be seen that not only is the likely quantity of vitamin $\mathrm{D}$ formed in skin considerably greater than the likely intake from non-fortified food, but it could also reach values regarded as potentially toxic, if such quantities were to be ingested ${ }^{(17)}$. Yet even with a high proportion of the total skin area being exposed for many days in summer, there is no evidence that the accumulating supply of vitamin $\mathrm{D}_{3}$ causes hypervitaminosis $\mathrm{D}$ toxicity.

Because vitamin $\mathrm{D}$ has been regarded as a micronutrient, it has been assumed that its supply from food and from its formation in skin were physiologically equivalent. But there are differences in their transport and rate of conversion to $25(\mathrm{OH}) \mathrm{D}$. Pre-vitamin $\mathrm{D}_{3}$ produced in skin undergoes heat stimulated isomerisation to vitamin $\mathrm{D}_{3}$ at a rate partly determined by the skin temperature and partly by the presence of the vitamin $\mathrm{D}$-specific-binding protein (DBP) in the fluid surrounding the keratinocytes in which the pre-vitamin $\mathrm{D}_{3}$ was produced. The high concentration of apo-DBP molecules in blood and extracellular fluid, each with a single binding site for vitamin $\mathrm{D}$ or its metabolites, enhances the rate of conversion of pre-vitamin $\mathrm{D}_{3}$ to vitamin $\mathrm{D}_{3}$ by tightly binding the vitamin $\mathrm{D}_{3}$ that diffuses from the skin cells, thus promoting the forward direction of this reversible isomerisation reaction ${ }^{(18,19)}$. This skin-derived vitamin $\mathrm{D}$ is then taken up by hepatic cells, a process that continues steadily for up to $7 \mathrm{~d}$ after a single exposure of skin to solar UV light ${ }^{(20)}$. In the liver cells, the vitamin $\mathrm{D}_{3}$ is 25 -hydroxylated by the microsomal enzyme CYP2R $1^{(21)}$ and the $25(\mathrm{OH}) \mathrm{D}_{3}$ then trickles into blood, induced to emerge from cells by the high-affinity, specific-binding sites of the plentiful apo-DBP in the circulation. Again, this accumulation of $25(\mathrm{OH}) \mathrm{D}_{3}$ in blood occurs slowly, taking between 7 and $14 \mathrm{~d}$ before the highest concentration is reached after a single exposure of skin to UV radiation $^{(22)}$.

Now, contrast this with the fate of orally delivered vitamin $\mathrm{D}$, where the mechanism and rate of delivery to the liver are quite different from those of vitamin D formed in skin. Dietary vitamin $\mathrm{D}$ is absorbed into intestinal mucosal cells in association with dietary fat ${ }^{(23)}$. This vitamin $\mathrm{D}$, along with triacylglycerols, phospholipids and cholesterol, then traverses the baso-lateral mucosal cell membrane in chylomicron lipid particles. This chylomicron lipid in the circulation is then incorporated as a bolus into hepatocytes, with up to $50 \%$ of the absorbed vitamin D taken up by those cells, in $1 \mathrm{~h}$ after entering the circulation ${ }^{(24,25)}$. Within hepatocytes, two metabolic processes occur simultaneously. One is the 25 -hydroxylation of the orally supplied vitamin D. The other is the processing of the chylomicron lipids into triglyceride- and cholesterol-containing, very-low-density lipoproteins $(\mathrm{VLDL})^{(26)}$. The $25(\mathrm{OH}) \mathrm{D}$ and VLDL products of these metabolic processes then exit the liver cells over the same time period, with the $25(\mathrm{OH}) \mathrm{D}$ being immediately bound to the apo-DBP in blood. However, because of the conformational similarity of vitamin D to cholesterol ${ }^{(27)}$, some of the $25(\mathrm{OH})$ $\mathrm{D}$ derived from oral vitamin $\mathrm{D}$ could become incorporated into the VLDL emerging from the liver cells.

The classical sign of vitamin D toxicity is hypercalcaemia, which occurs with persistent oral consumption of $250 \mu \mathrm{g} / \mathrm{d}$ 
Table 2. Potential yield of vitamin $D_{3}$ formed in skin from a single exposure to UV sunlight

\begin{tabular}{cccc}
\hline & $\begin{array}{l}5 \% \text { skin }^{\mathrm{a}} \\
\text { exposed }(\mu \mathrm{g})\end{array}$ & $\begin{array}{l}10 \% \text { skin }^{\mathrm{a}} \\
\text { exposed }(\mu \mathrm{g})\end{array}$ & $\begin{array}{l}20 \% \text { skin }^{\mathrm{a}} \\
\text { exposed }(\mu \mathrm{g})\end{array}$ \\
\hline $7-\mathrm{DHC}^{\mathrm{b}}$ at $0.5 \mu \mathrm{g} / \mathrm{cm}^{2}$ & 458 & 917 & 1834 \\
$\begin{array}{c}\text { Vitamin } \mathrm{D}_{3} \text { produced } \\
\text { at } 10 \% \text { conversion }\end{array}$ & 46 & 92 & 183 \\
$\begin{array}{c}\text { Vitamin } \mathrm{D}_{3} \text { produced } \\
\text { at } 20 \% \text { conversion }\end{array}$ & 92 & 183 & 367 \\
\hline
\end{tabular}

The yield of vitamin $D_{3}$ in skin, in response to exposure to UV light from the sun depends not only on the number of minutes of a single period of exposure, but also on many other variables, including the seasonal intensity of solar UVB radiation, absorption of UVB radiation by skin pigmentation, the age of the irradiated individual and the proportion of pre-vitamin $\mathrm{D}_{3}$ produced that is then converted by prolonged irradiation, to other non-biologically active products. Experiments with human skin, irradiated in vitro, have found up to $35 \%$ of total 7-DHC that can be converted to previtamin $D_{3}$ in a single exposure session ${ }^{(16)}$.

${ }^{a}$ Based on the calculated total skin area of an adult male of $18229 \mathrm{~cm}^{2(15)}$

${ }^{\mathrm{b}}$ Lowest concentration of $7-\mathrm{DHC}$ in skin, which ranges from $0.5-1.3 \mu \mathrm{g} / \mathrm{cm}^{2(12)}$.

or more ${ }^{(17)}$. The mechanism of this hypercalcaemic toxicity is attributed to an uncontrolled delivery of the vitamin $\mathrm{D}$ hormone, 1,25-dihydroxy vitamin $\mathrm{D}\left[1,25(\mathrm{OH})_{2} \mathrm{D}\right]$ to various cells which then promote excess calcium delivery into blood from both intestinal absorption and bone mineral mobilisation $^{(17)}$. The reason suggested for why $1,25(\mathrm{OH})_{2} \mathrm{D}$ is able to enter cells at random is because more of it becomes "free" when high concentrations of $25(\mathrm{OH}) \mathrm{D}$ occupy much of the specific binding sites on DBP in blood ${ }^{(17)}$. The high concentration of $25(\mathrm{OH}) \mathrm{D}$ in blood has not itself been regarded as the mediator of the toxicity. Yet large doses of oral vitamin D are used as a rodenticide and are able to kill rats and mice in as short a time as $1 \mathrm{~d}$ after oral ingestion ${ }^{(28)}$, when very high concentrations of $25(\mathrm{OH}) \mathrm{D}$ are found in blood $^{(29)}$.

An alternative hypothesis is that vitamin $\mathrm{D}$ toxicity is mediated not only by $1,25(\mathrm{OH})_{2} \mathrm{D}$ but rather by its far more plentiful precursor, $25(\mathrm{OH}) \mathrm{D}$. At good vitamin $\mathrm{D}$ status of $50-80 \mathrm{~nm} 25(\mathrm{OH}) \mathrm{D}$ in blood serum and with a normal DBP concentration of $4-8 \mu \mathrm{M}$, only about $0.03 \%$ of that 25 $(\mathrm{OH}) \mathrm{D}$ would not be tightly protein-bound ${ }^{(30)}$. Any of the unbound $25(\mathrm{OH}) \mathrm{D}$ that diffuses into cells, where there is no specific function for that metabolite, would quickly be induced to leave by the high concentration of apo-DBP in the extracellular environment. However, when $25(\mathrm{OH}) \mathrm{D}$ was added to aortic endothelial cell cultures, it became apparent that this vitamin $\mathrm{D}$ metabolite is quite cytotoxic, even at low concentrations (Fig. 1) ${ }^{(31)}$. It could thus be concluded that the very high concentration of apo-DBP in blood, relative to those of vitamin $\mathrm{D}$ and its metabolites, is an effective way of preventing the uncontrolled entry of $25(\mathrm{OH}) \mathrm{D}$ into cells.

The toxicity of orally supplied vitamin $\mathrm{D}$, independent of hypercalcaemia, has been demonstrated in several early studies in pigs, rabbits, rats and non-human primates. Angiotoxicity was the typical pathology found when vitamin $\mathrm{D}$ was fed in amounts that were greater than those needed to prevent deficiency, but considerably less than intakes causing hypercalcaemic toxicity. As an example of this arterial pathology, squirrel monkeys were fed daily doses of vitamin D that were five times higher than the amount required to maintain good vitamin D status ${ }^{(32)}$. The proliferation of myointimal cells and atheromatous plaques were found in the aorta of these animals (Fig. 2), but there was no hypercalcaemia nor calcium deposits in the arterial lesions. A yet unproven mechanism for the angiotoxicity in animal experiments, following repeated oral intake of vitamin $\mathrm{D}$, could be the toxic action of $25(\mathrm{OH}) \mathrm{D}$ trapped in VLDL, when delivered to the endothelial and smooth muscle cells of arteries.

The physiological supply of vitamin D by UV-induced formation in skin has evolved with transport and metabolism mechanisms that protect against the potential toxicity of 25 $(\mathrm{OH}) \mathrm{D}$, regardless of the amount of vitamin $\mathrm{D}$ being produced. Another essential and potentially toxic lipophilic substance, retinol (vitamin A), has also to be obtained from the environment. But, in comparison to vitamin $\mathrm{D}$, the vitamin A precursors, the carotenoids, are plentifully available in vegetarian foods. However, unlike orally supplied vitamin D, the mechanisms for metabolism and transport of vitamin A from food have evolved to protect against its potential toxicity ${ }^{(33)}$. The esterification of vitamin $\mathrm{A}$ with long-chain fatty acids, its complex storage process in hepatic stellate cells and its rigorously controlled release from the liver bound to the (a)

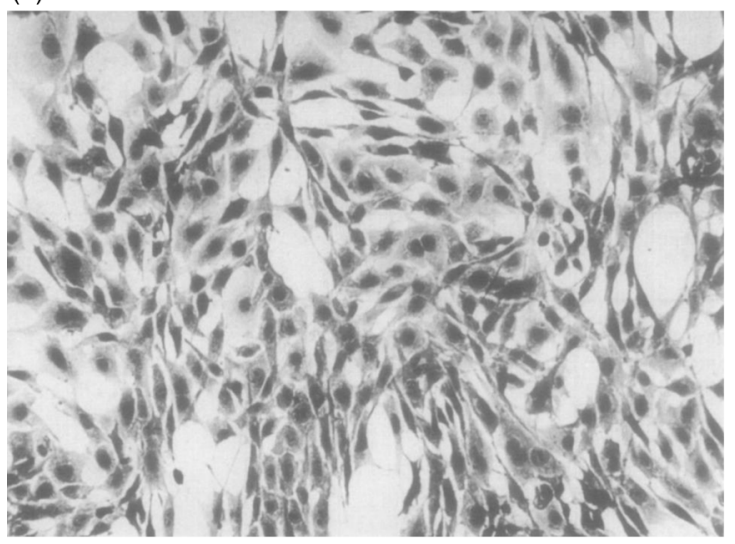

(b)

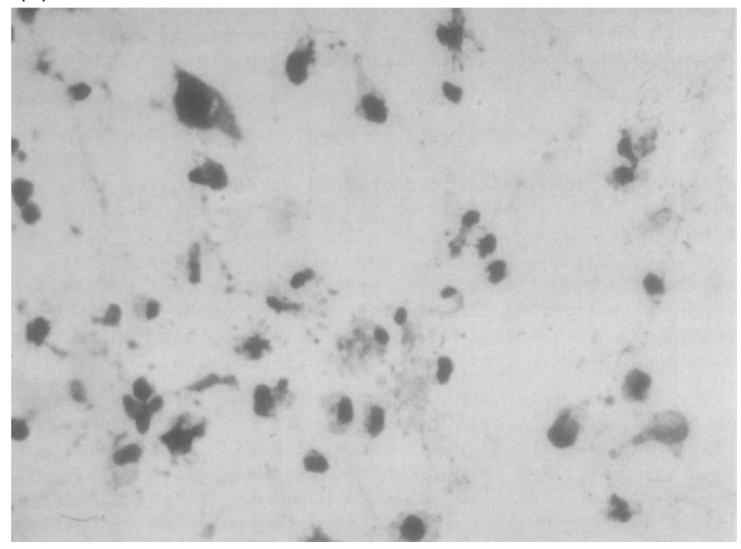

Fig. 1. Pig aortic endothelial cells grown in culture: (a) control cells and (b) cells exposed for $24 \mathrm{~h}$ to $300 \mathrm{~nm} 25(\mathrm{OH}) \mathrm{D}_{3}$. Reproduced from Levene and Lawson ${ }^{(31)}$. 
(a)
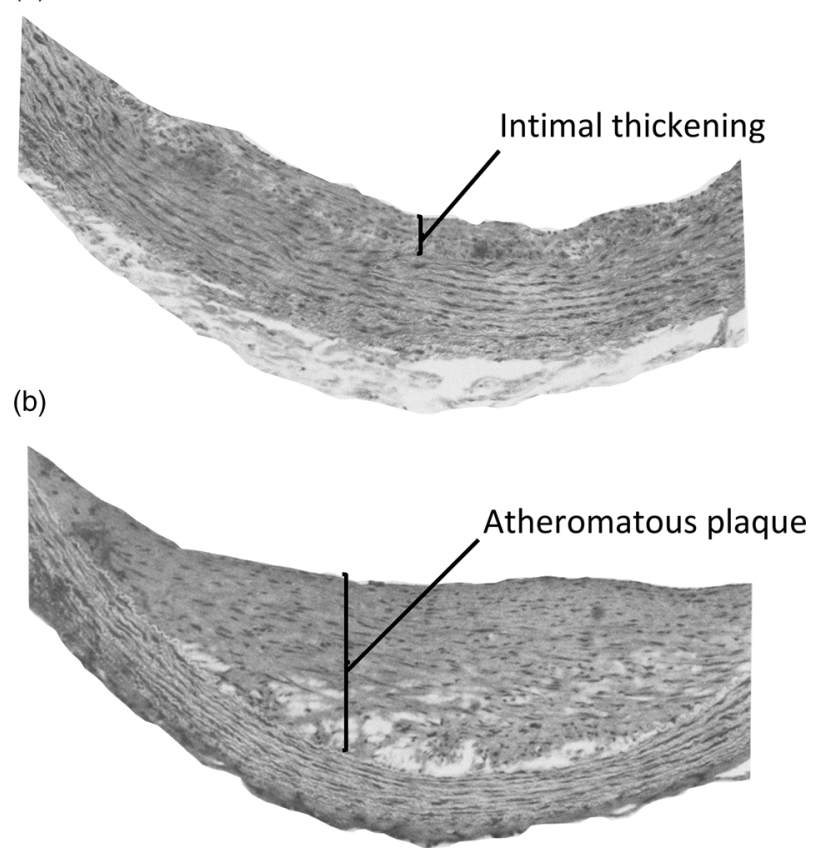

Fig. 2. Aortic lesions in squirrel monkeys given daily oral doses of vitamin D. Adult squirrel monkeys weighing $750-1000 \mathrm{~g}$ were given daily oral doses of $12.5 \mu \mathrm{g}$ vitamin $D_{3}$ for $10-18$ months with diets containing $0.5 \%$ cholesterol. Histological sections of the aorta of these animals showed (a) intimal thickening with proliferation of myointimal cells and (b) atheromatous plaques. No aortic lesions were reported in animals on control diets containing $0.5 \%$ cholesterol and providing $2.5 \mu \mathrm{g}$ vitamin $D_{3}$ per day. Reproduced with permission from Peng et al. ${ }^{(32)}$

retinol-binding protein enable it to be safely delivered to the many cells where it performs regulatory and structural functions ${ }^{(33)}$.

The processing of vitamin D produced in skin has evolved in a way that protects against potential toxicity. In contrast, the maintenance of adequate status by the continuous oral supply of vitamin $\mathrm{D}$ has only been a strategy for the last 100 years. Thus, no protective adaptation against any vitamin $\mathrm{D}$ toxicity by this route, unlike the physiological processing of vitamin A, has had time to evolve. Animal studies demonstrate that longterm maintenance of vitamin $\mathrm{D}$ status by supplying oral vitamin D may be associated with vascular pathology. It would therefore be wise to develop population strategies to avoid this potential vitamin $\mathrm{D}$ toxicity, which utilise the physiology of vitamin $\mathrm{D}$ formation in skin. One such strategy could be the controlled exposure of skin to UV light in the vitamin D-producing wavelength range of $290-320 \mathrm{~nm}$. However, the logistic of arranging this on a population basis, while preventing UV damage to skin cells, is a formidable challenge. An alternative method of obtaining vitamin D could be via transdermal administration, which would use the physiological transport and metabolism processes that have evolved to ensure a safe supply of this potentially toxic substance.

\section{References}

1. Yang H (2013) Conserved or lost: molecular evolution of the key gene GULO in vertebrate vitamin C biosynthesis. Biochem Genet 51, 413-425.
2. Havinga E (1973) Vitamin D, example and challenge. Experientia 29, 1181-1193. doi:10.1007/BF01935064.

3. Mellanby E (1918) The part played by an 'accessory factor' in the production of experimental rickets. J Physiol 52, xi-xii.

4. Engelsen $O$ (2010) The relationship between ultraviolet radiation exposure and vitamin D status. Nutrients 2, 482-495. doi:10.3390/ nu2050482.

5. O'Neill CM, Kazantzidis A, Ryan MJ, et al. (2016) Seasonal changes in vitamin D-effective UVB availability in Europe and associations with population serum 25-hydroxyvitamin D. Nutrients 8, 533. doi:10.3390/nu8090533.

6. Dunlop E, James AP, Cunningham J, et al. (2021) Vitamin D composition of Australian foods. Food Chem 358, 129836. doi:10.1016/j. foodchem.2021.129836.

7. Jakobsen J \& Christensen T (2021) Natural vitamin D in food: to what degree does 25-hydroxyvitamin $\mathrm{D}$ contribute to the vitamin D activity in food? JBMR Plus 5, e10453. doi:10.1002/ jbm4.10453.

8. Cashman KD, Seamans KM, Lucey AJ, et al. (2012) Relative effectiveness of oral 25-hydroxyvitamin D3 and vitamin D3 in raising wintertime serum 25-hydroxyvitamin $\mathrm{D}$ in older adults. Am J Clin Nutr 95, 1350-1356. doi:10.3945/ajcn.111.031427.

9. Cashman KD (2021) Global differences in vitamin D status and dietary intake: a review of the data. Endocr Connect 1, EC-21-0282. R1. doi:10.1530/EC-21-0282.

10. Ross AC, Taylor CL, Yaktine AL, et al. (editors) (2011) Dietary reference intakes for calcium and vitamin D. In Institute of Medicine (US) Committee to Review Dietary Reference Intakes for Vitamin $D$ and Calcium. Washington, DC: National Academies Press. doi:10.17226/13050.

11. Vik T, Try K \& Strømme JH (1980) The vitamin D status of man at 70 degrees north. Scand J Clin Lab Invest 40, 227-232.

12. MacLaughlin J \& Holick MF (1985) Aging decreases the capacity of human skin to produce vitamin D3. J Clin Invest 76, 1536-1538. doi:10.1172/JCI112134.

13. Webb AR, Kazantzidis A, Kift RC, et al. (2016) Colour counts: sunlight and skin type as drivers of vitamin D deficiency at UK latitudes. Nutrients 10, 457. doi:10.3390/nu10040457.

14. van Dijk A, den Outer P, van Kranen H, et al. (2016) The action spectrum for vitamin D3: initial skin reaction and prolonged exposure. Photochem Photobiol Sci 15, 896-909. doi:10.1039/ c6pp00034 g.

15. Lee JY, Choi JW \& Kim H (2008) Determination of body surface area and formulas to estimate body surface area using the alginate method. J Physiol Antbropol 27, 71-82. doi:10.2114/jpa2.27.71.

16. Obi-Tabot ET, Tian XQ, Chen TC, et al. (2000) A human skin equivalent model that mimics the photoproduction of vitamin D3 in human skin. In Vitro Cell Dev Biol Anim 36, 201-204. doi:10.1290/1071-2690(2000)036<0201:AHSEMT>2.0.CO;2.

17. Vieth R (2007) Vitamin D toxicity, policy, and science. J Bone Miner Res 22, 64-68.

18. Holick MF, MacLaughlin JA, Clark MB, et al. (1980) Photosynthesis of previtamin D3 in human skin and the physiologic consequences. Science 210, 203-205. doi:10.1126/science.6251551.

19. Duchow EG, Cooke NE, Seeman J, et al. (2019) Vitamin D binding protein is required to utilize skin-generated vitamin D. Proc Natl Acad Sci U S A 116, 24527-24532. doi:10.1073/pnas.1915442116.

20. Haddad JG, Matsuoka LY, Hollis BW, et al. (1993) Human plasma transport of vitamin D after its endogenous synthesis. J Clin Invest 91, 2552-2555. doi:10.1172/JCI116492.

21. Christakos S, Dhawan P, Verstuyf A, et al. (2016) Vitamin D: metabolism, molecular mechanism of action, and pleiotropic effects. Physiol Rev 96, 365-408. doi:10.1152/physrev.00014.2015.

22. Adams JS, Clemens TL, Parrish JA, et al. (1982) Vitamin-D synthesis and metabolism after ultraviolet irradiation of normal and vitamin-D-deficient subjects. $N$ Engl J Med 306, 722-725. doi:10.1056/NEJM198203253061206.

23. Silva MC \& Furlanetto TW (2018) Intestinal absorption of vitamin D: a systematic review. Nutr Rev 76, 60-76. doi:10.1093/nutrit/nux034. 
24. Dueland S, Helgerud P, Pedersen JI, et al. (1983) Plasma clearance, transfer, and distribution of vitamin D3 from intestinal lymph. Am J Physiol 245, E326-E331. doi:10.1152/ajpendo.1983.245.4.E326.

25. Haddad JG, Jennings AS \& Aw TC (1988) Vitamin D uptake and metabolism by perfused rat liver: influences of carrier proteins. Endocrinology 123, 498-504. doi:10.1210/endo-123-1-498.

26. Alves-Bezerra M \& Cohen DE (2017) Triglyceride metabolism in the liver. Compr Physiol 8, 1-8. doi:10.1002/cphy.c170012.

27. Fraser DR \& Kodicek E (1968) Conformational similarities of vitamin D and cholesterol as enzyme substrates. Nature 220, 10311032. doi:10.1038/2201031a0.

28. Greaves JH, Redfern R \& King RE (1974) Some properties of calciferol as a rodenticide. J Hyg (Lond) 73, 341-351. doi:10.1017/ s0022172400042686.
29. DeLuca HF, Prahl JM \& Plum LA (2011) 1,25-Dihydroxyvitamin $\mathrm{D}$ is not responsible for toxicity caused by vitamin $\mathrm{D}$ or 25-hydroxyvitamin D. Arch Biochem Biophys 505, 226-230.

30. Bikle DD \& Schwartz J (2019) Vitamin D binding protein, total and free vitamin D levels in different physiological and pathophysiological conditions. Front Endocrinol (Lausanne) 10, 317. doi:10.3389/ fendo.2019.00317.

31. Levene CI \& Lawson DEM (1977) A possible effect of vitamin D metabolites on cell adhesion. Cell Biol Int Rep 1, 93-97.

32. Peng SK, Taylor CB, Tham P, et al. (1978) Role of mild excesses of vitamin D3 in arteriosclerosis. A study in squirrel monkeys. Paroi Arterielle 4, 229-243.

33. de Oliveira MR (2015) Vitamin A and retinoids as mitochondrial toxicants. Oxid Med Cell Longev 2015, 140267. doi:10.1155/2015/140267. 